\title{
Pemetaan Risiko Pekerja Konstruksi Berbasis Metode Job Safety Analysis Di PT BBB
}

\author{
Ali Zainal Abidin ${ }^{1}$, Nina Aini Mahbubah ${ }^{2 *}$ \\ ${ }^{1,2}$ Program Studi Teknik Industri, Fakultas Teknik, Universitas Muhammadiyah Gresik \\ J1. Sumatera 101 GKB, Randuagung Gresik 61121, Indonesia \\ *Koresponden email: n.mahbubah@umg.ac.id, alizainal_170601@umg.ac.id
}

Diterima : 15 Juli 2021

Disetujui : 22 Juli 2021

\begin{abstract}
The growing rapid infrastructure jobs have been acknowledged in line with rapid development of instfrastructure project in this nation. PT BBB is a prominent construction enterprise with specialize in both corporate and government project. As such project profoundly depend on human worker, a number of accident occurred which caused delay to finish scheduled task. This study aim to mapping degree of accident risk in order to mitigate risk likelihood. Job Safety Analysis is used as research approach. This research begun in determining working activities breakdown, followed by describing and identifing hazards in each working activity, and finally propose a mitigating scenario in order to eliminate work accidents. The results showed that there were 208 accidents. Those accidents have been calculated from seven working activities breakdown. Furthermore, it is found 22 potential hazards with likelihood risk as follow : 4 potential hazards is consideredaas low level risk, 8 potential hazards is determined in moderate level risk, 6 potential hazard is classified in high level risk and finally 4 potential hazards is considered as extreme level risk.
\end{abstract}

Keywords : work accident, hazard, JSA, risk level, construction

\begin{abstract}
Abstrak
Perkembangan industri di Indonesia semakin banyak di ikuti dengan dampak era globalisasi saat ini, seperti di perkembangan perusahaan yang bergerak di bidang jasa konstruksi juga ikut mengalami kenaikan pesat. PT BBB merupakan salah satu perusahaan bergerak di bidang jasa konstruksi untuk membangun proyek pemerintah maupun proyek swasta. Dalam menyelesaikan suatu proyek perusahaan tidak lepas dari masalah kecelakaan kerja yang mengakibatkan delay penyelesaian pengerjaan proyek. Penelitian ini menggunakan metode Job Safety Analysis. Metode tersebut berisi langkah untuk mengetahui potensi bahaya yang ada pada aktivitas kerja di tempat kerja kemudian diberikan rumusan perbaikan guna meminimalisir risiko bahaya terjadi kembali. Langkah penelitian ini mengacu pada 4 tahap JSA yaitu menentukan proses kerja, menjabarkan proses kerja mengidentifikasi bahaya dari kecelakaan kerja dan mengendalikan risiko bahaya dalam upaya meminimalisir tingkat kecelakaan kerja terulang kembali. Tujuan dari penelitian yaitu mengidentifikasi risiko kemudian dilakukan analisis untuk mengetahui tingkatan dari risiko serta skenario usulan pengendalian risiko. Hasil dari penelitian menunjukkan terdapat 208 kasus kecelakaan kerja pada 7 aktivitas kerja. Kemudian ditemukan dari 22 potensi bahaya yang ada, 4 potensi bahaya termasuk risiko level ringan, 8 potensi bahaya termasuk risiko level sedang, 6 potensi bahaya termasuk risiko level tinggi, dan 4 potensi bahaya termasuk risiko level sangat berbahaya.
\end{abstract}

Kata Kunci : kecelakaan kerja, bahaya, JSA, level risiko, konstruksi

\section{Pendahuluan}

Pada saat ini kondisi perkembangan industri di Indonesia terlihat semakin berkembang ditandai dengan banyaknya pertumbuhan usaha baru dengan status kepemilikan pribadi maupun pemerintah. Penggunaan teknologi yang semakin berkembang ini memberikan kemudahan akses bagi pengguna, namun juga memberikan efek yang mungkin saja tidak dapat dihindari seperti bertambahnya jumlah kecelakaan dan risiko kerja serta semakin beragam sumber dari kecelakaan kerja bagi pengguna teknologi saat ini. Perkembangan industri juga terlihat di bidang jasa konstruksi dibuktikan dengan akhir-akhir ini menunjukkan pengembangan yang cukup signifikan, seperti pembangunan gedung, pabrik, hotel, mall, dan lain-lain yang semakin meningkat. Agar dapat memenuhi permintaan konsumen maka setiap perusahaan yang bergerak di bidang konstruksi haruslah selalu menganalisis dan memperbaiki kualitas insfrastruktur dari proyek yang dijalankan, hal itu memiliki dampak baik bagi perusahaan yaitu dapat mengetahui sumber 
permasalahan dan kecelakaan kerja yang sedang terjadi sehingga risikonya dapat dicegah dan tidak terulang kembali [1].

Indonesia saat ini mempunyai angka kecelakaan kerja yang masih tinggi dan meningkat dalam setiap tahunnya. Dalam data International Labor Organization (ILO) menunjukkan bahwa kasus kecelakaan kerja yang terjadi di Indonesia rata-rata pertahun sejumlah 99.000 kasus [2]. Sementara menurut data Badan Penyelenggara Jaminan Sosial (BPJS) mencatat jumlah kecelakaan sebagian besar atau skeitar $70 \%$ terjadi di lokasi kerja atau ketika bekerja. Diketahui bahwa tingginya kasus kecelakaan kerja dikarenakan karna penerapan SMK3 yang masih rendah. Sebagai upaya pengendalian dari risiko kecelakaan kerja perlu dilakukan identifikasi sumber bahaya yang ada di tempat kerja dan evaluasi risikonya serta diberikan pengendalian [1]. Seiring dengan pertumbuhan industri konstruksi saat ini maka keselamatan dan kesehatan pekerja juga harus diberikan perhatian utama [3]. Sumber daya manusia adalah bagian terpenting dalam mengelola seluruh proses kerja yang ada di setiap tempat kerja [4].

PT BBB merupakan salah satu perusahaan yang bergerak di bidang jasa konstruksi skala nasional berdiri tahun 2005 dan mengerjakan konstruksi korporasi ataupun proyek pemerintah. Perusahaan tersebut didirikan sebagai wujud dari bentuk loyalitas pemiliknya pada bidang kontruksi yang sudah lama dijalankan. Kini perusahaan tersebut sukses dan selalu berkembang karena memenuhi kepuasan pelanggan. Salah satu proyek yang sedang berlangsung saat ini yaitu proses pembangunan pabrik karet di Malang, Jawa Timur. Dengan adanya proses pembangunan saat ini perusahaan tersebut pasti menghadapi masalah salah satunya yaitu kecelakaan kerja. Fakta dilapangan menunjukkan bahwa pekerja kurang memperhatikan penggunaan APD yag sesuai, bimbingan tentang K3, arahan proses kerja. Akibat dari fakta dilapangan mengakibatkan pekerja mengalami kecelakaan kerja dalam risiko kecil sampai fatal dan juga zero accident tidak dapat dicapai oleh perusahaan tersebut.

PT BBB saat ini menggunakan teknologi yang maju dalam membangun infrastruktur proyek yang dijalankan, dan diketahui bahwa terdapat dampak faktor lingkungan kerja akibat proses kerja yang tidak memenuhi standar keselamatan dan kesehatan kerja. Dengan adanya sistem manajemen kerja yang bertujuan melindungi pekerja, maka pemerintah Indonesia mewajibkan setiap tempat kerja untuk mengimplementasikan sistem MK3 guna mencegah risiko dan meningkatkan level keselamatan kerja [5]. Risiko dan faktor bahaya ditempat kerja merupakan kondisi yang tidak mungkin dapat dihindari [6]. Dari risiko dan faktor bahaya dapat mengakibatkan kecelakaan kerja serta penyakit akibat kerja yang dapat merugikan tenaga kerja. Menurut [7] perusahaan yang bergerak di bidang jasa konstruksi dikenal sebagai pekerjaan yang tergolong high risk bagi pekerja di tempat kerja. Maka dengan itu setiap perusahaan harus selalu melakukan evaluasi dan peningkatan pengawasan pekerja.

Berdasarkan hasil observasi dan wawancara ditemukan kecelakaan kerja yang terjadi di PT BBB. Kecelakaan tersebut memiliki risiko bahaya kecil hingga fatal bagi pekerja di tempat kerja. Hal tersebut terjadi karena pekerja selalu mengabaikan arahan SOP kerja saat di lapangan. Dengan masih ditemukannya kecelakaan kerja yang berakibat pekerja mengalami cidera ringan hingga fatal menunjukkan bahwa penerapan K3 masih rendah sehinggah perlu dilakukan analisis lebih lanjut agar risiko dapat diminimalisir. Menurut ref. [8] mendefinisikan keselamatan dan kesehatan kerja yaitu suatu kondisi yang bisa mempengaruhi keselamatan dan kesehatan tenaga kerja, karyawan tetap, tamu yang berada di tempat kerja. Faktor penentu dari penerapan budaya K3 yaitu manajemen perusahaan, peraturan K3 serta keterlibatan karyawan dalam mejalankan prinsip dari K3. Menurut UU No.1 Tahun 1970, kecelakaan kerja didefinisikan sebagai suatu kejadian yang tidak terduga sebelumnya dan tidak diharapkan terjadi, dimana dapat menimbulkan kerugian secara finansial maupun korban manusia [9]. Penyebab dari kecelakaan kerja dapat disebabkan oleh unsafe action yang tidak melakukan proses penyelamatan diri dan dapat disebabkan oleh kondisi unsafe condition [10].

Job safety analysis (JSA) adalah suatu metode yang berisi beberapa langkah kerja dalam mengidentifikasi dan menganalisis potensi bahaya yang ada di tempat kerja [11]. JSA juga dapat didefinisikan sebagai pemeriksaan prosedur untuk mengetahui apakah pekerjaan yangtengah dilakukan berjalan sesuai SOP yang sesuai [12]. Tujuan dari penggunaan metode JSA yaitu untuk mengidentifikasi potensi bahaya di setiap aktivitas kerja sehingga pekerja di tempat kerja dapat terjamin keselamatan dan kesehatan kerjanya. Menurut [13], penggunaan metode JSA memiliki manfaat dan keuntungan sebagai berikut :

1. Meningkatkan produktifitas pekerjadi tempat kerja

2. Dapat memberikan contoh prosedur kerja yang sesuai

3. Mengidentifikasi APD apa saja yang dibuthkan saat bekerja

4. Melakukan review terhadap pekerja dalam setiap proses kerja yang dilaksanakan

5. Melakukan studi untuk pekerja apabila diperlukan improvement SOP kerja. 
Menurut ref. [12] [11], dalam melakukan analisa potensi bahaya pekerjaan menggunakan metode JSA terdapat 4 langkah dasar, yaitu :

1. Menentukan proses kerja yang akan dianalisis

2. Menjabarkan proses kerja menjadi langkah dasar

3. Mengidentifikasi bahaya dari kecelakaan kerja pada proses kerja yang dipilih

4. Mengendalikan risiko bahaya dalam upaya meminimalisir tingkat kecelakaan kerja terulang kembali.

Penerapan JSA di perusahaan hilir bergerak pada Industri Gas Skala Multinasional menunjukkan adanya perbaikan signifikan dalam mitigasi kecelakaan kerja [9]. Metode JSA berhasil mengidentifikasi secara terperinci 3 potensi bahaya dengan klasifikasi bahaya medium dikarenakan faktor human error. Metode JSA juga terbukti efektif menurunkan risiko kecelakaan kerja di perusahaan manufaktur [14]. Klasifikasi level bahaya dan pemetaan berdasarkan risiko bahaya terbukti mampu menurunkan risiko kecelakaan kerja di perusahaan yang memproduksi tepung kelapa tersebut. Efektifitas metode JSA dalam meminimalisisr tingkat kecelakaan kerja terjadi dan menanggulangi risiko akibat kerja kerja [7][8] ]maka pendekatan JSA merupakan pendekatan yang tepat untuk diimplementasikan di pekerjaan konstruksi seperti PT BBB. Metode ini berisi serangkaian langkah untuk mengetahui potensi bahaya apa saja yang adapada aktivitas kerja di tempat kerja kemudian diberikan rumusan perbaikan guna meminimalisir risiko bahaya terjadi kembali [13]. Penelitian ini bertujuan untuk mengidentifikasi risiko yang ada di PT BBB selanjutnya melakukan pemetaan untuk mengetahui tingkatan dari risiko tersebut serta diberikan pengendalian untuk periode kedepan.

\section{Metode Penelitian}

Penelitian ini menggunakan pendekatan deskriptif eksplanatori dengan menerapkan metode yang telah digunakan dan di implementasikan pada penelitian terdahulu yang pernah dilakukan oleh [1] mengenai penggunaan JSA dalam identifikasi risiko kecelakaan kerja di bagian workshop PT. Total Dwi Daya Kota semarang. Temuan dari penelitian ini yaitu terdapat jenis risiko kecelakaan kerja sehingga harus dilakukan peningkatan pengawasan terhadap pekerja serta pelatiahan tenaga kerja.

Pengumpulan data dilakukan secara observasi berbasis walk through survey dan menggunakan instrument lembar check list dan desain kuesioner. Adapun responden pada penelitian ini adalah pekerja yang berjumlah 6 orang expert dibagian konstruksi dan 1 orang manajemen K3 pada proyek yang sedang berjalan.

Data kuantitatif yang dikumpulkan adalah breakdown pekerjaan dan jumlah kecelakaan kerja yang terjadi selama 1 tahun kerja yaitu pada periode bulan Januari hingga Desember tahun 2020. Selanjutnya di identifikasi breakdown aktivitas kegiatan yang dilakukan pekerja di lapangan, potensi dan risiko bahaya yang ada di PT BBB dalam proses pembangunan pabrik karet tersebut. Responden mengisi kuesioner berupa penilaian risiko yang merupakan hasil rata-rata dari data responden serta tabel JSA untuk pengendalian risiko yang ada. Adapun desain kuesioner dapat dilihat pada Tabel 1.

Tabel 1. Desain kuesioner responden

\begin{tabular}{cl}
\hline No. & Pertanyaan \\
\hline 1. & Aktivitas kegiatan apa saja yang dilakukan pekerja dilapangan dalam menyelesaikan sebuah proyek di \\
PT. BBB? & Apakah pernah terjadi kejadian kecelakaan kerja selama berlangsungnya penyelesaian sebuah proyek \\
2. & di PT. BBB ? dan jumlahnya berapa? \\
3. Apa saja faktor/sumber penyebab terjadinya kecelakaan kerja di PT. BBB \\
4. Berdasarkan sumber bahaya tersebut, dampak apa saja yang ditimbulkan untuk para pekerja di PT. BBB \\
?. Bagaimanakah tindakan atau peran manajemen dalam menyelesaikan kecelakaan kerja di PT. BBB ?
\end{tabular}

Dalam melakukan proses identifikasi risiko berdasarkan pada kriteria AS/NZS 4360 [15] untuk mengetahui tingkatan dan dampak dari kecelakaan kerja yang sedang terjadi. Terdapat berbagai macam teknik identifikasi dan analisis risiko yang ada ditempat kerja yaitu dilakukan secara kualitatif, semi maupun kuantitatif. Teknik tersebut memiliki tujuan untuk membantu dalam meminimalisir tingkat kecelakaan kerja terjadi [16]. Adapun kriteria dapat dilihat pada Tabel 2 dan Tabel 3. 
Tabel 2. Kriteria Likelihood

\begin{tabular}{|c|c|c|}
\hline \multirow{2}{*}{ Level } & \multirow{2}{*}{ Kriteria } & \\
\hline & & Kualitatif \\
\hline 1 & Jarang Terjadi & $\begin{array}{l}\text { Insiden dimana diperkirakan terjadi tetapi hanya pada } \\
\text { keadaan kritis }\end{array}$ \\
\hline 2 & $\begin{array}{l}\text { Kemungkinan Kecil } \\
\text { terjadi }\end{array}$ & Insiden yang kemungkinan terjadi pada waktu tertentu \\
\hline 3 & Mungkin terjadi & $\begin{array}{l}\text { Insiden yang akan terjadi dan kemungkinan terjadi } \\
\text { disuatu tempat }\end{array}$ \\
\hline 4 & $\begin{array}{l}\text { Kemungkinan besar } \\
\text { terjadi }\end{array}$ & $\begin{array}{l}\text { Insiden yang terjadi dengan mudah dan berkala di } \\
\text { semua kondisi }\end{array}$ \\
\hline 5 & Hampir pasti terjadi & Insiden yang sering terjadi dihampir semua kondisi \\
\hline
\end{tabular}
Sumber : AS/NZS 4360 (1999)

Tabel 3. Kriteria Severity

\begin{tabular}{ccl}
\hline Level & Uraian & \multicolumn{1}{c}{$\begin{array}{c}\text { Deskripsi } \\
\text { Keparahan Cidera }\end{array}$} \\
\hline 1 & Insignificant & $\begin{array}{l}\text { Insiden yang tidak berdampak kerugian atau cidera pada } \\
\text { pekerja } \\
\text { Insiden yang berdampak muncul cidera ringan, kerugian } \\
\text { finansial kecil } \\
\text { Insiden yang menimbulkan cidera berat dan perlu dirawat } \\
\text { dan kerugian finansial sedang } \\
\text { Insiden yang mengakibatkan cidera parah dan cacat tetap } \\
\text { serta kerugian finansial besar dan mengangu } \\
\text { kelangsungan bisnis } \\
\text { Insiden yang menimbulkan kejadian fatal yaitu korban } \\
\text { Majeninggal dan kerugian finansial parah }\end{array}$ \\
\hline & Catastrophic & Sumber : AS/NZS 4360 (1999)
\end{tabular}

Dalam melakukan proses analisis risiko memiliki tujuan untuk menentukan besarnya risiko dari kecelakaan kerja yang terjadi [17]. Adapun analisa risiko didapat dari kombinasi antara tingkat likelihood dan tingkat severety. Setelah diketahui tingkatan dari risiko yang terjadi maka dilakukan pembobotan nilai berdasarkan metode wawancara dan kuisioner dengan tenaga kerja yang berada di tempat kerja. Dari hasil tersebut dikembangkan menjadi peringkat risiko dari kombinasi antara likelihood dan severity [18]. Adapaun skala tingkatan bahaya dari risiko yang terjadi dapat dilihat pada Tabel 4.

Tabel 4. Skala tingkatan bahaya (Risk Level)

\begin{tabular}{ccccccc}
\hline \multirow{2}{*}{ Skala } & & \multicolumn{5}{c}{ Severity } \\
\cline { 3 - 7 } & & 1 & 2 & 3 & 4 & 5 \\
\hline \multirow{3}{*}{ Likelihood } & 1 & $\mathrm{H}$ & $\mathrm{H}$ & $\mathrm{E}$ & $\mathrm{E}$ & $\mathrm{E}$ \\
& 2 & $\mathrm{M}$ & $\mathrm{H}$ & $\mathrm{H}$ & $\mathrm{E}$ & $\mathrm{E}$ \\
& 3 & $\mathrm{~L}$ & $\mathrm{M}$ & $\mathrm{H}$ & $\mathrm{E}$ & $\mathrm{E}$ \\
& 4 & $\mathrm{~L}$ & $\mathrm{~L}$ & $\mathrm{M}$ & $\mathrm{H}$ & $\mathrm{E}$ \\
& 5 & $\mathrm{~L}$ & $\mathrm{~L}$ & $\mathrm{M}$ & $\mathrm{H}$ & $\mathrm{H}$ \\
\hline \multicolumn{7}{c}{ Sumber : AS/NZS 4360 (1999) }
\end{tabular}

\section{Hasil dan Pembahasan}

Identifikasi pertama yang dihasilkan pada penerapan metode JSA di proyek konstruksi ini yaitu data mengenai kecelakaan kerja yang terjadi selama 12 bulan di tahun 2020. Adapun tabel jumlah kecelakaan kerja dapat dilihat pada Tabel 5.

Tabel 5. Jumlah kecelakaan Di PT BBB

\begin{tabular}{ccccc}
\hline Bulan & Jumlah & \multicolumn{3}{c}{ Jenis Kecelakaan } \\
\cline { 3 - 5 } & Kecelakaan & Ringan & Sedang & Berat \\
\hline Januari & 14 & 14 & 0 & 0 \\
Februari & 15 & 14 & 1 & 0 \\
Maret & 21 & 19 & 2 & 0 \\
April & 13 & 13 & 0 & 0 \\
Mei & 12 & 12 & 0 & 0 \\
\hline & & 2114 &
\end{tabular}




\begin{tabular}{ccccc}
\hline Juni & 15 & 12 & 2 & 1 \\
Juli & 22 & 22 & 0 & 0 \\
Agustus & 25 & 22 & 3 & 0 \\
September & 15 & 12 & 2 & 1 \\
Oktober & 18 & 18 & 0 & 0 \\
November & 20 & 19 & 1 & 0 \\
Desember & 18 & 0 & 0 \\
\hline & \multicolumn{2}{c}{ Sumber : PT BBB (2021) }
\end{tabular}

Dari Tabel 5 dapat diketahui bahwa pada periode 1 tahun, kecelakaan kerja terjadi pada setiap bulannya di PT BBB. Jumlah kecelakaan tertinggi terjadi di bulan Agustus dan terendah terjadi di bulan Mei. Jika ditotal dalam 1 tahun yaitu di tahun 2020, kecelakaan kerja terjadi sebanyak 208 kejadian dengan rincian jenis kecelakaan ringan sebanyak 195 kejadian, jenis kecelakaan sedang sebanyak 11 kejadian dan jenis kecelakaan berat sebanyak 2 kejadian. Dari jumlah kecelakaan kerja yang terjadi maka perlu dilakukan analisis lebih lanjut mengenai kegiatan kerja yang ada ditempat kerja guna mengetahui sumber risiko yang ada.

Tabel 6. Gambar pekerjaan di lapangan

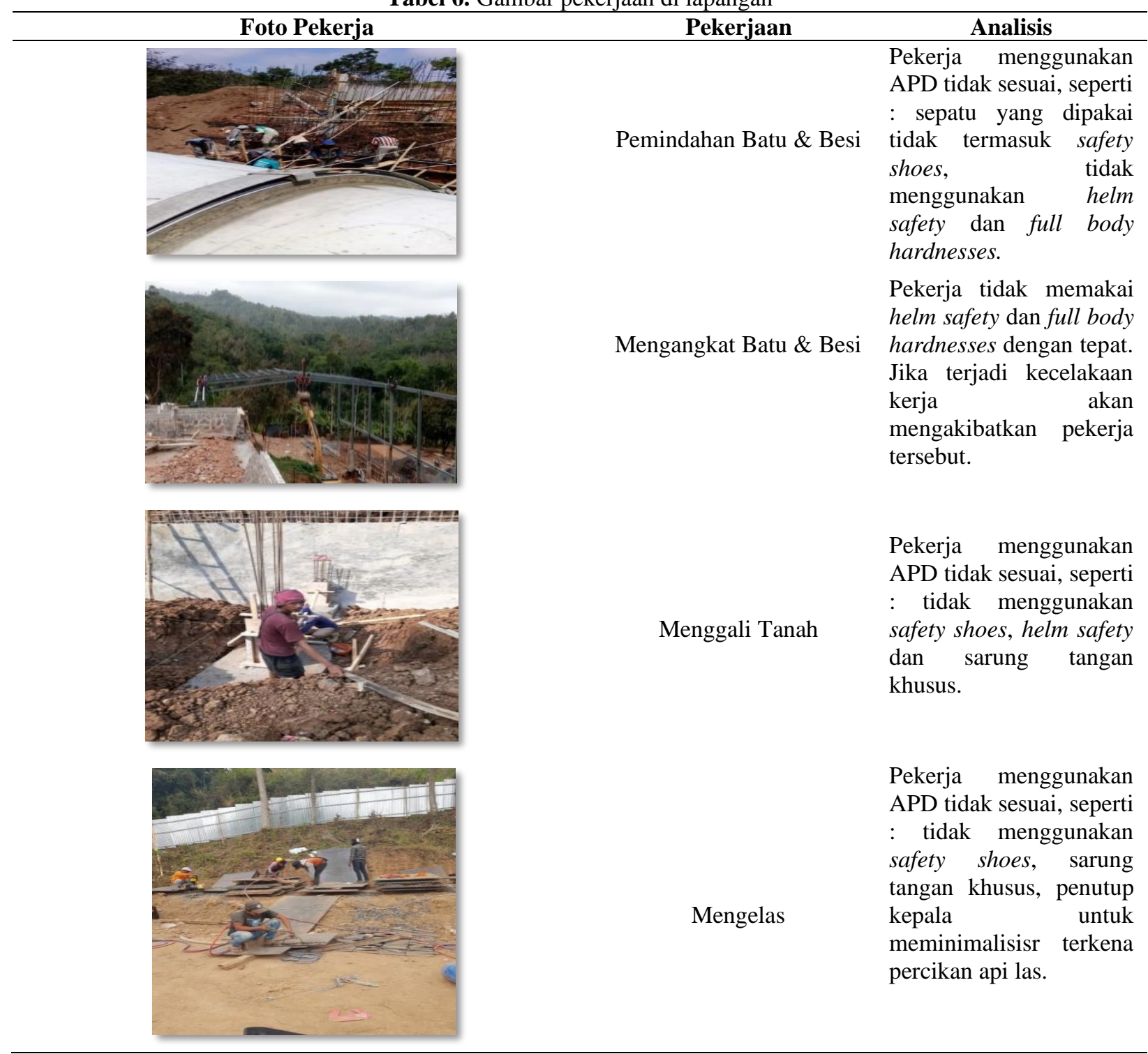



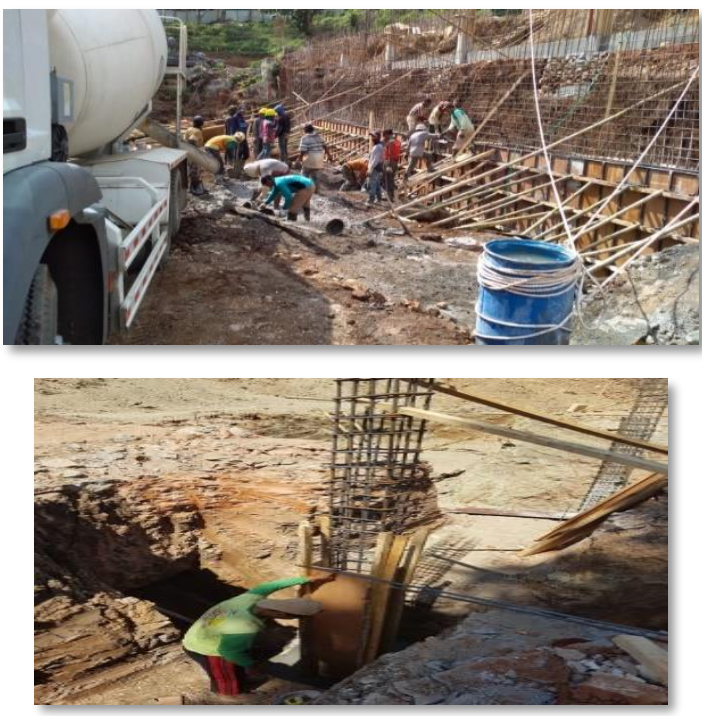

Pekerja tidak memakai helm safety dan full body hardnesses dengan tepat. Jika terjadi kecelakaan kerja akan mengakibatkan pekerja tersebut.

Pekerja menggunakan APD tidak sesuai, seperti :tidak menggunakan safety shoes, helm safety dan sarung tangan khusus

Sumber : Data diolah (2021)

Dari Tabel 6 dapat diketahui mengenai aktivitas pekerjaan yang ada di PT BBB saat menyelesaikan proyek pembangunan pabrik karet di Kabupaten Malang, dibuktikan dengan lampiran gambar yang ada dari setiap proses kerja. Dari gambar dalam Tabel 6 selanjutnya dilakukan analisis mengenai kedisiplinan tenaga kerja dalam memakai APD saat di tempat kerja. APD merupakan salah satu alat yang dapat meminimalisir dampak jika kecelakaan kerja terjadi. Hasil dari analisis tersebut menunjukkan bahwa masih banyak pekerja yang kurang memperhatikan penggunaan APD yang tidak sesuai dengan SOP yang ada. Jika hal itu terus dilakukan maka akan membahayakan bagi tenaga kerja.

Tabel 7. Identifikasi bahaya, penilaian risiko dan penentuan level risiko

\begin{tabular}{|c|c|c|c|c|c|c|}
\hline \multirow[t]{2}{*}{ Aktivitas } & \multirow[t]{2}{*}{ Penyebab } & \multirow[t]{2}{*}{ Dampak } & \multicolumn{2}{|c|}{$\begin{array}{l}\text { Analisis } \\
\text { Risiko }\end{array}$} & \multirow[t]{2}{*}{ Skor } & \multirow[t]{2}{*}{ Kategori } \\
\hline & & & $\mathrm{L}$ & $S$ & & \\
\hline Menggali & Tidak memakai APD & Terpeleset & 3 & 2 & 6 & M \\
\hline \multirow[t]{3}{*}{ Tanah } & dengan tepat, kondisi & Terjatuh & 3 & 2 & 6 & M \\
\hline & lingkungan yang licin & Tertimpa tanah & 3 & 3 & 9 & $\mathrm{H}$ \\
\hline & Tidak memakai sarung & Tertimpa material & 2 & 5 & 10 & $\mathrm{E}$ \\
\hline Pemindahan & tangan, jari tangan & Tangan terjepit & 4 & 2 & 8 & $\mathrm{H}$ \\
\hline \multirow[t]{2}{*}{ Batu \& Besi } & tergores sisi yang tajam & Terkilir & 3 & 2 & 6 & M \\
\hline & & Terbentur material & 2 & 4 & 8 & $\mathrm{H}$ \\
\hline Mengangkat & Benda yang diangkat & Terpeleset \& cidera & 3 & 2 & 6 & M \\
\hline \multirow[t]{2}{*}{ Batu \& Besi } & $\begin{array}{c}\text { terjatuh karna salah posisi } \\
\text { saat mengangkat }\end{array}$ & Terkilir & 3 & 2 & 6 & M \\
\hline & & $\begin{array}{l}\text { Terkena percikan } \\
\text { bunga api }\end{array}$ & 2 & 5 & 10 & $\mathrm{E}$ \\
\hline \multirow[t]{4}{*}{$\begin{array}{l}\text { Mengelas } \\
\text { Pondasi }\end{array}$} & $\begin{array}{l}\text { Percikan api dari benda } \\
\text { kerja, kabel las }\end{array}$ & $\begin{array}{l}\text { Tersengat aliran } \\
\text { listrik }\end{array}$ & 2 & 5 & 10 & $\mathrm{E}$ \\
\hline & mengelupas & $\begin{array}{l}\text { Mata perih setelah } \\
\text { welding }\end{array}$ & 2 & 5 & 10 & $\mathrm{E}$ \\
\hline & & Menghirup asap las & 2 & 4 & 8 & $\mathrm{H}$ \\
\hline & Posisi tubuh yang salah & Terpeleset & 3 & 2 & 6 & M \\
\hline \multirow[t]{2}{*}{ Mengecor } & saat bekerja, area kerja & Kulit sobek & 3 & 3 & 9 & $\mathrm{H}$ \\
\hline & licin & Terjatuh & 2 & 4 & 8 & $\mathrm{H}$ \\
\hline \multirow[t]{4}{*}{ Mengecat } & $\begin{array}{c}\text { Area kerja basah, kondisi } \\
\text { tangga yang tidak kuat }\end{array}$ & $\begin{array}{l}\text { Jatuh dari } \\
\text { ketinggian }\end{array}$ & 2 & 3 & 6 & M \\
\hline & dan tidak ada pegangan & Tertimpa sisa cat & 1 & 1 & 1 & $\mathrm{~L}$ \\
\hline & & Terpeleset & 2 & 2 & 4 & $\mathrm{~L}$ \\
\hline & Posisi paku dan jari & Tangan Terjepit & 2 & 2 & 4 & $\mathrm{~L}$ \\
\hline \multirow[t]{2}{*}{ Memaku } & tangan yang salah, terkena & Tangan sobek & 3 & 2 & 6 & M \\
\hline & sisi tajam pada paku & $\begin{array}{l}\text { Tersayat ujung } \\
\text { paku }\end{array}$ & 1 & 2 & 2 & $\mathrm{~L}$ \\
\hline
\end{tabular}

Sumber : Data Diolah (2021) 
Pada Tabel 7 dapat diketahui bahwa dari hasil penilaian risiko di PT BBB ditemukan 22 potensi bahaya dari 7 aktivitas proses kerja yang dilakukan tenaga kerja di tempat kerja. Adapun klasifikasinya sebagai berikut 4 potensi bahaya dikategorikan sebagai tingkatan risiko level low, 8 potensi bahaya dikategorikan sebagai tingkatan risiko level moderate, 6 potensi bahaya dikategorikan sebagai tingkatan risiko level high dan 4 potensi dikategorikan sebagai tingkatan risiko level extreme. Aktivitas kerja yang memiliki potensi bahaya level medium dan high harus dilakukan analisis lebih lanjutagar dapat mengurangi angka kecelakaan kerja serta diharapkan kecelakaan tersebut tidak terjadi kembali.

Adapun potensi bahaya yang memiliki potensi bahaya level extreme harus benar-benar diprioritaskan untuk dilakukan evaluasi agar tingkat kecelakaan kerja dapat diminimalisisr. Setelah diketahui tingkatan risiko kemudian diberikan pengendalian untuk semua potensi bahaya dengan catatan bahwa potensi bahaya yang memiliki level extreme harus diperioritaskan terlebih dahulu. Skenario lembar kerja pengendalian risiko kecelakaan kerja ditabulasikan pada Tabel 8.

Tabel 8. Job Safety Analysis pada aktivitas pekerjaan di PT BBB

\begin{tabular}{|c|c|c|}
\hline $\begin{array}{l}\text { Nama Pekerjaan : Proyek } \\
\text { Bangunan Pabrik Karet } \\
\text { Pancursari Malang }\end{array}$ & Halaman : 1 & Tanggal : 6 Juni 2021 \\
\hline Peralatan : & Supervisor : & Analisis Oleh : Ali Zainal Abidin \\
\hline $\begin{array}{l}\text { Bagian :Las, tali, paku, } \\
\text { kuas, cangkul }\end{array}$ & Disetujui Oleh : & \\
\hline \multicolumn{3}{|c|}{ APD yang diperlukan : sarung tangan, safety shoes, helm safety, penutup kepala, full body hardness } \\
\hline \multirow[t]{3}{*}{ Aktivitas Pekerjaan } & Potensi Bahaya & Pengendalian \\
\hline & 1a.Terpeleset & 1a. Menggunakan safety shoes \\
\hline & $\begin{array}{l}\text { 1b. Terjatuh } \\
\text { 1c. Tertimpa tanah }\end{array}$ & $\begin{array}{l}\text { 1b. Menggunakan alat bantu untuk memudahkan } \\
\text { menggali tanah }\end{array}$ \\
\hline \multirow{6}{*}{ Menggali Tanah } & & 1c.1. Membuat SOP menggali tanah \\
\hline & & 1c.2. Menggunakan helm safety \\
\hline & & 1c.3. Meletakkan galian tanah berserakan \\
\hline & 2a. Tertimpa material & 2a.1 Menggunakan helm safety \\
\hline & 2b. Tangan terjepit & 2a.2. Meletakkan material pada tempatnya \\
\hline & 2c. Terkilir & 2b.1. Memperhatikan posisi tangan sebelum melakukan \\
\hline \multirow[t]{7}{*}{ Pemindahan Batu \& Besi } & & pekerjaan \\
\hline & & 2b.2. Menggunakan sarung tangan \\
\hline & & 2b.3 Membuat SOP melakukan pekerjaan \\
\hline & & 2c.1. Memindahkan benda menggunakan gerobak \\
\hline & & 2c.2. Mengangkat benda dengan dibantu pekerja lain \\
\hline & 3a. Terbentur material & 3a.1. Jaga jarak saat memindahkan material \\
\hline & 3b. Terpeleset \& cidera & 3a.2. Memberikan tanda yang mudah dilihat \\
\hline \multirow[t]{7}{*}{ Mengangkat Batu \& Besi } & 3c. Terkilir & 3b.1. Menggunakan safety shoes \\
\hline & & 3b.2. Membuat SOP untuk melakukan pekerjaan \\
\hline & & 3c.1. Memindahkan benda menggunakan gerobak \\
\hline & & 3c.2. Mengangkat benda dengan dibantu pekerja lain \\
\hline & $\begin{array}{l}\text { 4a. Terkena percikan } \\
\text { bunga api }\end{array}$ & $\begin{array}{l}\text { 4a.1. Menggunakan APD sarung tangan dan kaca mata } \\
\text { pelindung }\end{array}$ \\
\hline & 4b. Tersengat aliran listrik & 4a.2 Membuat SOP pekerjaan \\
\hline & 4c. Menghirup asap las & 4b.1. Menggunakan Mesin dengan tegangan rendah \\
\hline \multirow[t]{13}{*}{ Mengelas Pondasi } & 4d. Sakit mata & 4b.2. Menggunakan alat penurun tegangan otomatis \\
\hline & & 4b.3 Membuat SOP dalam menyalakan mesin \\
\hline & & 4c.1. Memberikan ventilasi yang cukup pada rungan \\
\hline & & las/di tempat terbuka \\
\hline & & 4c.2 Menggunakan respirator \\
\hline & & 4d. Menggunakan safety googles, faceshield \\
\hline & 5a. Terpeleset & 5a.1. Menggunakan safety shoes \\
\hline & 5b. Kulit sobek & 5a.2. Membuat SOP untuk melakukan pekerjaan \\
\hline & 5c. Terjatuh & 5a.3 Membersihkan area mengecor agar selalu bersih \\
\hline & & dan tidak licin \\
\hline & & 5b.1. Menggunakan sarung tangan \\
\hline & & 5b.2. Memegang pada sisi benda yang tidak tajam \\
\hline & & $\begin{array}{l}\text { 5c. Menggunakan alat bantu untuk memudahkan } \\
\text { melakukan pekerjaan. }\end{array}$ \\
\hline
\end{tabular}


6a. Jatuh dari ketinggian 6b. Tertimpa sisa cat

Mengecat 6c. Terpeleset

7a. Tangan Terjepit

7b. Tangan sobek

7c. Tersayat ujung paku
Memaku 6a.1. Menggunakan alat bantu untuk memudahkan melakukan pekerjaan 6a.2 Menggunakan APD lengkap 6b.1. Membuat SOP pekerjaan 6b.2. Melakukan pekerjaan dibantu pekerja lain 7a.1. Memlihat lebih jelas posisi tangan sebelum melakukan pekerjaan

7a.2. Menggunakan sarung tangan

7a.3 Membuat SOP melakukan pekerjaan

7b.1. Menggunakan sarung tangan

7b.2. Memegang pada sisi benda yang tidak tajam

7c.1 Menggunakan Sarung tangan

7c.2. Memegang pada sisi paku yang tidak tajam.

Sumber : Data Diolah (2021)

\section{Kesimpulan}

Berdasarkan analisis mengenai penerapan JSA dalam identifikasi dan analisis risiko kecelakaan kerja di PT BBB maka terdapat dua point kesimpulan yaitu yang pertama jumlah kecelakaan kerja yang terjadi di PT BBB pada periode Januari hingga Desember pada tahun 2020 ditemukan kecelakaan kerja sebanyak 208 kejadian dengan rincian jenis kecelakaan ringan sebanyak 195 kejadian, jenis kecelakaan sedang sebanyak 11 kejadian dan jenis kecelakaan berat sebanyak 2 kejadian. Kedua, dari hasil penelitian dengan metode JSA ditemukan 22 potensi bahaya dari 7 aktivitas proses kerja di PT. BBB, dimana 4 potensi bahaya merupakan level low risk, 8 potensi bahaya level moderate risk, 6 potensi bahaya merupakan level high risk dan 4 potensi bahaya merupakan level extreme risk.

Saran bagi pekerja di PT BBB yaitu perlu menjalankan instruksi kerja sesuai dengan SOP yang ada, menjaga jarak antara material dan pekerja, tidak membawa beban yang terlalu berat serta menggunakan APD yang tepat dan sesuai standar yang ada. Kelemahan penelitian ini yaitu obyek penelitian hanya dilakukan pada salah satu dari beberapa project yang tengah berjalan. Kelemahan kedua yaitu pada penelitian ini yaitu tidak dilakukan analisis mengenai action tidak aman pekerja dalam melakukan aktivitas pekerjaan. Penelitian lanjutan diharapkan mengacu pada pendekatan Behaviour Based Safety (BBS) dengan fokus pada risk action dibandingkan risk condition, sehingga dihasilkan penelitian yang komprehensif.

\section{Referensi}

[1] Tegar Bramasto and Intan Zainafree, "Penggunaan Job Safety Analysis Dalam Identifikasi Risisko Kecelakaan Kerja Di Bagian Workshop PT. Total Dwi Daya Kota Semarang," Unnes Journal Of Public Health, Vol. 4, No. 4, pp. 94-106, 2015.

[2] Nova Rosdiana, Shanti Kirana Anggraeni, and Ani Umyati, "Identifikasi Risiko Kecelakaan Kerja Pada Area Produksi Proyek Jembatan Dengan Metode Job Safety Analysis (JSA)," Jurnal Teknik Industri, Vol. 5, No. 1, pp. 1-6, 2017.

[3] Jeferson Bawang, Paul A. T. Kawatu, and Ribka Wowor, "Analisis Potensi Bahaya Dengan Menggunakan Metode Job Safety Analysis Di Bagian Pengapalan Site Pakal PT. Aneka Tambang Tbk. UBPN Maluku Utara," Jurnal KESMAS, Vol. 7, No. 5, 2018.

[4] Isdiyati , Endang Suhendra, and Nana Suyana, "Analisis Keselamata Kerja Menggunakan Metode Hazard Identification Risk Assesment Dengan Pendekatan Spar-H Pada Pt. Argha Perdana Kencana," Jurnal Ilmiah Teknik Industri, Vol. 9, No. 1, pp. 1-9, 2021.

[5] Meilan Agustin, "Identifikasi Bahaya Keselamatan Dan Kesehatan Kerja Serta Upaya Pengendalian Pada Proses Pengelasan Di Workshop," Jurnal KaLIBRASI - Karya Lintas Ilmu Bidang Rekayasa Arsitektur, Sipil, Industri, Vol. 8, No. 1, pp. 14-23, 2013.

[6] Moch Nur Amirudin, Priyo Agus Setiawan, and Haidar Natsir Amrullah, "Identifikasi Bahaya Kegiatan Maintenance Perusahaan Bioethanol Pada Unit Mekanik Dengan Metode JSA," in Proceeding 2nd Conference on Safety Engineering and Its Application, Vol. 2, S, pp. 809-814, 2018.

[7] Alfina Fitri Damayanti and Nina Aini Mahbubah, "Implementasi Metode Hazard Identification Risk Assessment and Risk Control Guna Peningkatan Keselamatan dan Kesehatan Karyawan Di PT ABC," Jurnal Serambi Enginering, Vol. VI, No. 2, pp. 1694-1701, 2021.

[8] 18001:2007 OHSAS, Occupational Health And Safety Assessment Series - Guideline For The., 1999. 
[9] Yahdi Ilmansyah, Nina Aini Mahbubah, and Dzakiyah Widyaningrum, "Penerapan Job Safety Analysis Sebagai Upaya Pencegahan Kecelakaan Kerja Dan Perbaikan Keselamatan Kerja Di PT. Shell Indonesia," Jurnal Proficiensi, Vol. 8, No. 1, pp. 15-22, 2020.

[10] Dewi Wulandari and Noeroel Widajati, "Risk Assessment Pada Pekerja Pengelasan Perkapalan Dengan Pendekatan Job Safety Analysis," The Indonesian Journal of Occupational Safety and Health, Vol. 6, No. 1, pp. 1-15, 2017.

[11] Paulus Sukapto, Harjoto Djojosubroto, and Handy Permana, "Penerapan Metode Job Safety Analysis and Risk Score untuk Meningkatkan Keselamatan dan Kesehatan Kerja pada Departemen Printing, Sewing dan Assembly PT. PAI, Bandung (Suatu Pendekatan Participatory Ergonomic)," Jurnal Kesehatan, vol. 9, No. 3, pp. 403-411, 2018.

[12] Nurkholis and Gusti Adriansyah, "Pengendalian Bahaya Kerja Dengan Metode Job Safety Analysis PdaPenerimaan Afval Lokal Bagian Warehouse Di PT. ST," Teknika : Engineering and Sains Journal, Vol. 1, No. 1, pp. 11-16, 2017.

[13] Maulana Arif Umaindra and Singgih Saptadi, "Identifikasi Dan Analisis Risiko Kecelakaan Kerja Dengan Metode JSA (Job Safety Analysis) Di Departemen Smoothmill PT Ebako Nusantara," Industrial Engineering Online Journal, Vol. 7, No. 1, 2018.

[14] Monalisa F. Sumampouw, Diana V. Doda, and Effendi P. Sitanggang, "Analisis Potensi Bahaya Dan Tingkat Risiko Dengan menggunakan Metode Job Safety Analysis (JSA) Pada Bagian Produksi Salah Satu Industri Tepung Kelapa," Journal Paradigma Sehat, Vol. 5, No. 3, pp. 59-74, 2017.

[15] Standards Australia License/New Zealand Standard, AZ/NZS 4360:1999 Risk Management. Brisbane: Standards Association of Australia, PO Box 1055, Strathfield NSW 2135, 1999.

[16] Al Asyhar Wahyu Azady, Evi Widowati, and Sri Ratna Rahayu, "Penggunaan Job Hazard Analysis dalam Identifikasi Risiko Keselamatan Kerja pada Pengrajin Logam," Higeia Journal Of Public Health Research And Development, Vol. 2, No. 4, pp. 510-519, 2018.

[17] Rani Aulia Imran, "Identifikasi Hazard Pada Proses Produksi Billet pada Area Tungku Peleburan Dengan Metode Hirarc (Studi Kasus PT XYZ)," Jurnal Ilmiah Teknik Industri, Vol. 8, No. 3, pp. 153-160, 2020.

[18] Pandu Martino, Dyah Ika Rinawati, and Rani Rumita, "Analisis Identifikasi Bahaya Kecelakaan Kerja Menggunakan Job Safety Analysis (JSA) Dengan Pendekatan Hazard Identification, Risk Assessment And Risk Control (HIRARC) di PT. Charoen Pokphand Indonesia- Semarang," Industrial Engineering Online Journal, Vol. 4, No. 2, 2018. 